\title{
COMMUNICATION
}

\section{Conversation with Dr. Steve Smale and Dr. Lee Hartwell}

\section{Indika Rajapakse}

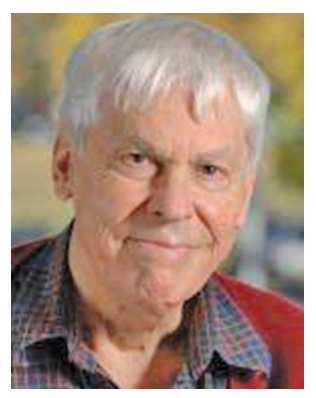

Dr. Steve Smale

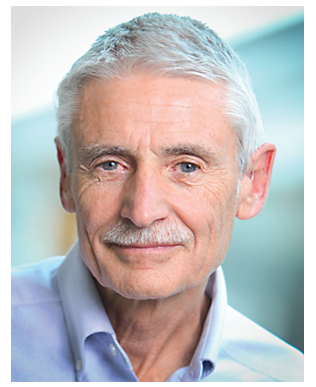

Dr. Lee Hartwell
It has been a privilege to interact with Dr. Steve Smale and Dr. Lee Hartwell both scientifically and personally. Dr. Smale received the Fields Medal in 1966 for proving a generalized version of the Poincaré conjecture. Dr. Hartwell won a Nobel prize in 2001 for discovering key regulators of the cell cycle. Unquestionably, their contributions to mathematics and biology independently advanced their fields. These seemingly disparate fields may also have a role to play together. I foresee solutions in human medicine by unifying beautiful biological questions with solid mathematical foundations and imagination. By sharing this interview I conducted with Dr. Smale and Dr. Hartwell together, I hope to encourage thinking about this unification, bring to light some possibilities for science, and especially to inspire young scientists and all of us to cultivate imagination.

Rajapakse: Do you have any advice on approaching a problem in science?

Indika Rajapakse is an associate professor of computational medicine and bioinformatics (Medical School), associate professor of mathematics, and associate professor of biomedical engineering at the University of Michigan, Ann Arbor. He is also a Member of the Smale Institute. His email address is indikar Qumich.edu.

For permission to reprint this article, please contact:

reprint-permission@ams .org.

DOI: https://doi.org/10.1090/noti2356
Smale: I think a lot of science has to do with formulating problems rather than answering them. Sometimes answering problems can be revolutionary but it's more important to understand what the problems are in a subject. It's my feeling that formulation of problems is pretty key.

Hartwell: I agree entirely with Dr. Smale, in fact what I am trying to emphasize in science education is the questions rather than the answers. I think the formulation of the question really defines the problem, it puts boundaries on what we're trying to figure out.

Rajapakse: In 1998, Dr. Smale formulated 18 problems for this century [Sma98]. Some have been solved and some are still open. He in fact wrote a paper in 1991 about the great problems and the attempts that failed. Dr. Hartwell, is there anything like this in biology?

Hartwell: Science magazine used to do this yearly survey of scientists to ask them what would be the great discoveries they could imagine in the next decade. I was always surprised by how pedestrian the answers were: they were simple extensions of what everybody was doing right now. I think there is a lack of imagination in biology, and it's because the reductionist approach to science is so successful. I don't see anybody formulating the big questions.

Rajapakse: Dr. Smale, you previously told me that biology is not like physics. Would you elaborate on this thought?

Smale: My view is that a goal for scientists in biology would be to make biology be inspired by physics. Mathematics has helped physics establish very firm foundations, dating back to Newton and even before. A role mathematics can play in biology is to give it a more clear picture of the foundations and eventually it can evolve as well. I worked in physics and a little biology but physics is so much more amenable to analysis than biology because of its foundations in math. Math can give biology a more sound foundation. 
Rajapakse: Dr. Hartwell has said that you can predict the future if you know something well. So perhaps that's where mathematics can come into play in biology. Dynamical systems (what Dr. Smale has done so much work in) is all about predicting the future. What do you think about this, Dr. Hartwell?

Hartwell: I think in science education, we spend too much time teaching students what's known, and not enough time teaching students what's unknown. In thinking about how you clarify the known and the unknown, how do you define what's known and unknown? Qualitative predictions are meaningless. If we take the definition, "to know something" means to quantitatively predict its future behavior, then of course that's mathematics.

Rajapakse: The paper "From molecular to modular cell biology" [HHLM99] is a beautiful paper with ideas that I believe interest people in many different fields. Nearly 20 years after writing this paper, what are your thoughts about how these ideas can connect fields, Dr. Hartwell?

Hartwell: [laughing] For me this paper was an attempt to communicate to physicists what interesting questions there were in biology. And so it was a collaboration between Stan Leibler who was a physicist and Andrew Murray who was a biologist like me, and they met for several days in Santa Fe and talked this through. John Hopfield, who is also a physicist, later added his comments through Stan. I think what makes this perhaps interesting and meaningful to you is the fact that it actually is fairly vague. It speaks about problems with a vagueness that allows and encourages a lot of imagination. And so I think maybe it challenges your imagination and you enjoy that. I don't see it as coming to profound conclusions but perhaps it is useful in the context that we're talking about, which is raising questions.

Rajapakse: Dr. Hartwell, what is simple advice you can give to young scientists?

Hartwell: My advice is to follow your own interests and your own instincts. That's very difficult advice to follow, because of all the restraints on the way people judge people for careers and grants and publications and things like that. So I think that people tend to follow the herd and do the things which are popular at the moment rather than bringing their own creativity to the problems because they are likely to see things and be interested in things in a different way than everyone else. But this takes a lot of courage and persistence, and it may be costly to actually allow your originality to express itself.

Rajapakse: Dr. Smale, could you tell me what problems you solved to get the Fields Medal in 1966?

Smale: I got the Fields Medal for what is called the Poincaré conjecture. I answered the Poincare conjecture for dimensional manifolds bigger than four, which has to do with the structure of manifolds. It's an idea in topology. What is the structure of spaces or a space that we live in? Mathematical versions have lots to do with things like homology and advances in what is called topology. At the same time I got the Fields Medal partly for my beginning work in dynamical systems, which for me is a bigger question for biologists than topology. Ordinary differential equations play a big role in science, but there's been a revolution in mathematics for 50 years or more, which makes it into a global subject. It's not just solving an equation or looking at numerical trajectories, but it has to do with looking at the global picture of dynamics. It's a huge revolution in mathematics. It has changed from ordinary differential equations to dynamical systems. This has not made an entrance into biological thinking, even for biologists who use mathematics. They do not seem to be aware of the great things one can do for global studies in science coming from ordinary differential equations through dynamical systems. Or, just ordinary differential equations from a global point of view.

Rajapakse: Dr. Hartwell, there is also your amazing discovery on cell cycle checkpoints which won a Nobel Prize in 2001. Can you briefly mention your contribution?

Hartwell: It was for identifying certain genes that were important in cell division. I think the more important contribution to biology was actually introducing cell biologists to yeast because yeast had been an organism that had only been studied by geneticists. Cell biology was studied primarily by visual means and biochemical means but not by genetics. So by introducing cell biologists to yeast as an organism in which to study cell biological problems, I think that's turned out to be very fruitful.

Hartwell: I have a question for Dr. Smale. Biological systems accumulate enormous amounts of variation by mutation. Unless the mutation is detrimental to the point of being lethal, or inhibiting or reducing reproduction, it stays in the population. So we have this huge variation in all populations, and every individual is different from every other individual, except for identical twins, and even there, there are epigenetic phenomena that change. My question is, how is biology organized so that it can tolerate all this variation? How is it organized in such a way that variation is constrained to always make the same thing?

Smale: I don't think I have any good answer for that. I believe that biology can use a lot more modern dynamics that's modeled on how things move in time or how they evolve eventually.

Rajapakse: Dr. Smale, I think Dr. Hartwell is thinking about some aspect of the basins. There is variability but still there is a stable system. 
Smale: When I say dynamical systems, a huge aspect of that is stability and some local dynamical senses, or stability of the whole system. Dynamical systems study what properties of systems are stable under perturbations. This is part of what I mean when I say that biologists can use more modern versions of ordinary differential equations which emphasize things like stability questions, noble questions, topological questions if you want.

Rajapakse: Dr. Smale, you apply math to economics too, right? Smale: Yeah, well I am an economist. I was in the economics department at Berkeley so I spent a decade working in economics. My whole goal in economics is to understand dynamics in economics: how do prices adjust? I wrote many papers towards that end and failed to find the main answers. What I came off of was a very clever question which I think is perhaps the main question of theoretical economics: how do prices adjust? You can write down several models for one commodity, and you can have one clean model of how supply complies with demand. For several commodities, it's an unsolved problem. In economics, that's a question of dynamics within economics, a question of global dynamics. How do prices achieve equilibrium? It's a fundamental question for theoretical economics.

Rajapakse: Is there an analogy in biology for that, Dr. Hartwell?

Hartwell: Well it sounds like a similar kind of problem where you have a lot of diversity in the economy and things coalesce to some stable state. That sounds a lot like the problem that we have in biology of creating the same thing with a lot of variation.

Rajapakse: Dr. Hartwell, do you think public interest or support for science has changed in the last decade? Under the circumstances can you see the public becoming more engaged in science and evidence-based policy?

Hartwell: Well at the present time I see this huge division in the US, and I think in the world, in that there are those who respect science and evidence to use in policy and those who disparage it and think we're best off without science and without information. It's amazing to me but these two trends are very prominent in the US and it's not a minor position to disparage science.

Rajapakse: What do you think, Dr. Smale?

Smale: I agree [with Dr. Hartwell], though I don't always know the truth of what's happening in other areas of science and the public.

Rajapakse: How do you identify a good problem in your field?

Smale: I think for me it's probably just a question of understanding the field of mathematics or some other field, like economics. Trying to understand what is important and what's the logic for developing the theory of that field is what matters most. I tend to see that the basic problem for theoretical economics is to understand how supply eventually equates to demand. That's something we see all around us and it's the stability of our economic system.

Rajapakse: So this applies to biology where there is a certain degree of uncertainty and error in measurements and control of variables, but is there value in replicating the work of others? Can you comment on the emphasis scientific journals place on novelty, Dr. Hartwell?

Hartwell: I think it's the opposite. I think they don't place that much emphasis on novelty. For example, the value of epidemiology is that it can reveal unexpected, unknown relationships and find things that are correlated. But epidemiologists tell me it's very hard to get published with just a correlation. There needs to be a rational, biological rationale for the correlation in order to get published. But this is exactly backward. The whole value of epidemiology is to reveal the correlation and then let people try and find the biological reasons for this.

Rajapakse: Dr. Hartwell, what is the most meaningful thing you do in your day?

Hartwell: What I'm finding most rewarding now is working with students. In the laboratory, the most fun part was always talking with the graduate students and postdocs and thinking together about problems. I do the same thing now with undergraduates in a course environment where they are trying to think of questions and experiments in a research environment. In a way, it has not really changed.

Rajapakse: Do you want to comment on your interactions with students, Dr. Smale?

Smale: I've had about 50 students write a PhD thesis. But in the last decade I've had almost no contact with students.

Rajapakse: I like to think I am (one of your students), Dr. Smale. I want to go back to when you were advising students, you were very relaxed, right?

Smale: Correct, I was very relaxed and if they had any questions and so on I would give them advice on what they can work on with some idea about it. I would leave them on their own initiative to do work and it worked okay because 50 of them got their PhD.

Rajapakse: Did you meet with them each week?

Smale: No, sometimes they came and asked me things. But there were no scheduled meetings.

Rajapakse: Isn't this a bit different in biology, Dr. Hartwell?

Hartwell: One thing was the same. I always encouraged my students to be independent. They came up with their own research ideas and problems, but we would talk almost daily. 
Rajapakse: Do you think it is a good thing, Dr. Hartwell, now, for people who are in this interdisciplinary world to communicate often?

Hartwell: I think it's more important to communicate broadly. Students do tend to be isolated in laboratory groups. Once a group gets as big as 10 people, there is almost no outside communication. I really like the way the biochemistry department was. They would set up laboratories where students work together from different advisors. The ability for students to interact broadly with people is missing in biology.

Rajapakse: Scientific research is becoming more and more interdisciplinary. In your opinion, is the current curriculum relevant enough to meet this challenge?

Hartwell: I don't think I have any answers, but what I do feel is that disciplines often can fill up their training with a lot of courses and information and material that's very narrow. Disciplines have only a few broad principles that you need for thinking about the discipline, and that we should find ways of training students much more broadly to understand the fundamental assumptions and principles within a field, or how a field solved problems rather than all the problems it has solved.

Smale: One thing I have often thought is students (and myself too) working on mathematical problems early means a lot less technical training. A lot of universities' advice is to have the students learn so many techniques and that's a mistake. Students can start doing interesting and important research at a much younger stage of their career than what usually happens. I would give problems or ideas to students for them to work on. These are things that are not demanding or require a large technical background.

Rajapakse: This is very close to the "Science of Me," right, Dr. Hartwell?

Hartwell: I want naive students to be able to think about original research problems and that's not always easy because many research areas require a lot of prior knowledge and a lot of expensive equipment.

Smale: I think one thing to take into account is modern communications, especially Google, which allows students to learn many things and they can browse through research and they can latch on to the techniques that they need to develop. It's the same thing in many fields of math and science.

Hartwell: I agree entirely. The advent of information online has eliminated the need for a lot of courses that students take.
Smale: When I was a student I would go to the library and check out as many books as I could carry and take them home for a few days. Now I never go to a library.

Rajapakse: But Dr. Smale, you still print papers, right?

Smale: Oh yeah, I cannot remember so well, so I print out some pages of the paper.

Rajapakse: Dr. Hartwell, do you print?

Hartwell: Not very much. I'm not really reading the research literature in any field. I'm much more involved in student education from a sort of design point of view rather than an information point of view.

Rajapakse: What do you think about the future, Dr. Hartwell? To me, this new [COVID-19] vaccine is amazing within a year. An RNA-based vaccine is amazing. What do you see in the future in the next 10 years?

Hartwell: I think the main thing that impresses me about how things are changing is from the perspective of sensory perception. I realize now how very limited our sensory perception is, and how complicated the world is that we have to function in. I think the augmentation of human cognitive and sensory capability with technology is really what's going to change.

Rajapakse: Dr. Smale, do you use technology in medicine?

Smale: I spend a fair amount of time on the internet browsing rather than reading articles. I find a little bit of information about things that are important for my health. I learned to reject most medical authorities that way.

Rajapakse: Dr. Smale, what do you think of the role of math in the future?

Smale: Oh, I don't know. Oftentimes I'm not exactly enthusiastic about work. Much of mathematics is becoming too technical. I would like to see math and research become less technical, but I don't know if that will change.

Rajapakse: Dr. Smale, you also worked on the mathematics of vision, correct? How did you get interested in this?

Smale: I think it's because I paid attention to what people were doing around me and I had friends like Tommy Poggio back 20 years ago. Eventually we started working on processing vision, artificial vision, and human vision. The different levels of the brain that correspond to people seeing something, it goes through different levels and it is not too much different from artificial vision.

Rajapakse: Your 18th problem is on the limits of intelligence, right? What did you mean there?

Smale: Learning and intelligence, understanding them both in the machine and human side and the interchange between the two is what this is about. I lost my reasons to defend it or explain it today because so many people are doing it. Some are coming from computer science and 


\section{COMMUNICATION}

they are trying to understand the consciousness of a machine. Can a machine feel pain? They don't have the answer but it's an interesting question.

Rajapakse: You have said that you believe math will be helpful in biology. Do you still think working together with mathematicians in biology and other fields can contribute to our understanding?

Hartwell: Absolutely, I wish that I could understand math better. As I mentioned earlier, I think the definition of knowing something is being able to quantitatively predict it. So mathematics is really the foundation of science. It's a language of science.

Rajapakse: Dr. Hartwell, you know that for more than two years, Dr. Smale, myself, and Charles Pugh have been working on a problem related to synchronization. I am learning so much from Dr. Smale and how he thinks about synchronization from a geometric point of view. It's a simple problem but it's so beautiful. Maybe someday we three can meet again.

Hartwell: Okay thank you for getting us together. It's been fun.

Smale: Good to see you again.

Rajapakse: Thank you so much, bye.

ACKNOWLEDGMENTS. I would like to thank members of my lab, including Stephen Lindsly, Can Chen, Gabrielle Dotson, Cooper Stansbury, Walter Meixner, and Lindsey Muir, for helping me to formulate questions and readying this interview for publication.

\section{References}

[HHLM99] Leland H. Hartwell, John J. Hopfield, Stanislas Leibler, and Andrew W. Murray, From molecular to modular cell biology, Nature 402 (December 1999), no. 6761, C47C52.

[Sma98] Steve Smale, Mathematical problems for the next century, Math. Intelligencer 20 (1998), no. 2, 7-15, DOI 10.1007/BF03025291. MR1631413

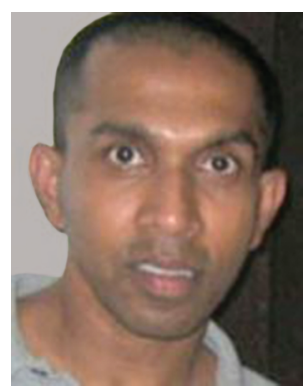

Indika Rajapakse

Credits

Photo of Lee Hartwell is courtesy of Theresa Naujack. Photo of Steve Smale is courtesy of Indika Rajapakse. Photo of Indika Rajapakse is courtesy of Lindsey Muir.

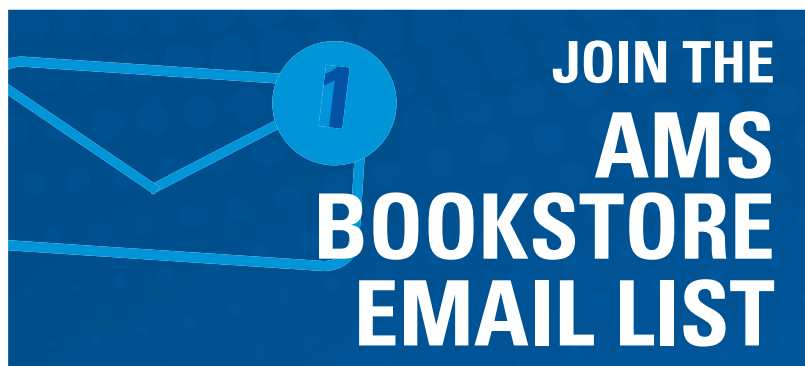

Be the first to learn about:

- Publishing highlights

- New titles being released

- Monthly sales

- Special discounts on AMS publications
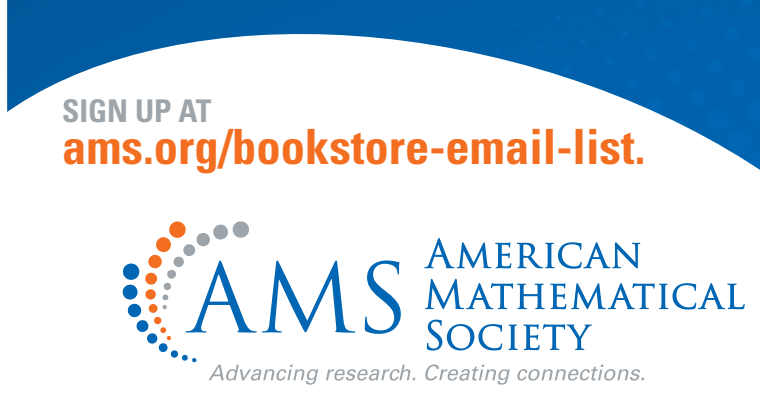